\title{
Mulheres pecuaristas e a decisão gerencial em Dom Pedrito - RS
}

\author{
Tatielle Belem Langbecker ${ }^{1}$ \\ Thaís Arrué Melo Gonçalves ${ }^{2}$
}

\begin{abstract}
Resumo
As posições socioeconômicas ocupadas por homens e mulheres, especialmente no meio rural, são marcadas por assimetrias de poder entre os sexos que estabelecem as relações de gênero. Assim, a perspectiva de gênero possibilita o conhecimento e a compreensão das dinâmicas rurais, explicitando as desigualdades de gênero materializadas na distribuição do poder, no acesso a recursos e no posicionamento nos processos decisórios. A opção pela pecuária de corte se dá por ser uma atividade dita masculina, assim como por suas contribuições socioeconômicas na formação do Rio Grande do Sul, mantendo sua importância no Estado. O objetivo é caracterizar a decisão gerencial de mulheres pecuaristas residentes no município de Dom Pedrito em sua atividade. Em termos metodológicos, baseia-se no estudo de caso múltiplo, utilizando-se de entrevistas para a geração dos dados, e a análise estatística descritiva verificou-se com o auxílio de planilhas do Excel. A maioria das entrevistadas afirmou que toma decisão em conjunto com outras pessoas. A tradição familiar foi o item que mais gerou variações dentre as perspectivas apontadas. Os dados indicaram que $85 \%$ das entrevistadas tomam decisões racionais muito frequentemente ou sempre. As participantes inserem seus estilos de gerenciamento e processos decisórios, ponderando os ensinamentos familiares com os aspectos contemporâneos de gerenciamento.
\end{abstract}

Palavras-chave: Pecuária. Relações de gênero.

\begin{abstract}
Socioeconomic positions occupied by men and women, especially in rural, are marked by asymmetries of power between the sexes that establish gender relations. Thus, the gender perspective allows knowledge and understanding of rural dynamics explaining gender inequalities materialized in the distribution of power, access to resources and position in decision-making. The choice of beef cattle is by being a male such activity, as well as by their socioeconomic contributions in the formation of Rio Grande do Sul, keeping their importance in the state. The goal is to characterize the managerial decision to ranchers women living in Dom Pedrito, in its activity. In terms of methodology is based on multiple case study, using interviews for the generation of data and the statistical analysis it was found with the help of Excel spreadsheets. Most respondents said that decision-making is held in conjunction with others. The family tradition was the item that generated the most variations among the prospects identified. The data indicated that 85\% of respondents make rational decisions very often or always. Participants enter their styles of management and decision-making, weighting the family learning with contemporary aspects of management.
\end{abstract}

Keywords: Gender relations and livestock.

\section{Introdução}

A mulher, historicamente, ocupa uma posição culturalmente conhecida como feminina, imposta pela sociedade, seja em espaços públicos ou familiares, fruto de construções sociais que delimitam as fronteiras entre o que é ser feminino e masculino. Com isso, torna-se nítida a tradicional comparação entre o que é atividade de mulheres e o que é atividade de homens, tratando-se, aqui, de uma discussão que busca identificar a figura feminina no meio rural, inserida na atividade pecuária de corte, especificamente.

\footnotetext{
${ }^{1}$ Doutoranda em Extensão Rural. Universidade Federal de Santa Maria (UFSM). tatielle.belem@gmail.com

${ }^{2}$ Mestranda em Extensão Rural. Universidade Federal de Santa Maria (UFSM). thaisamdp@hotmail.com
} 
Observam-se algumas modificações no cenário em que a mulher se insere, o que identifica uma tomada de poder, seja ele representado por elementos econômicos ou sociais. Isso possibilita o reconhecimento da mulher como agente público e auxilia na desconstrução, mesmo que de forma lenta, dos princípios que posicionam a mulher como agente submisso a uma conduta preestabelecida.

A definição de rural também sofreu modificações, pois, por longos períodos, este ambiente era percebido como sinônimo de pobreza e isolamento. Não se desconsideram as inúmeras situações que concordam com essa ideia, entretanto surgem percepções que entendem o rural como solução de problemas. Essa visão percebe alternativas de melhora na vida rural, tais como a melhoria da qualidade vida, por meio do contato com a natureza e pelas relações sociais mais pessoais, mais frequentes entre a população do campo (WANDERLEY, 2001).

O rural, de acordo com Wanderley (2001), não está em situação isolada, com lógicas exclusivas de funcionamento e independentes do restante da sociedade, ou seja, é fundamental mencionar as especificidades históricas, culturais, sociais e ambientais que o delineiam em sua própria realidade. Dentre os diversos elementos que o compõem, a autora refere-se a dois que ganham destaque na caracterização do rural: o espaço físico, resultante da construção social produzida pela ocupação territorial, pela dominação social e pela relação com a cidade; e a representação de um espaço como lugar de vida, fundamentado em identidades específicas.

Assim como o entendimento sobre o rural, o desenvolvimento rural também reflete diferentes versões de compreensão, especialmente ao mencionar sua trajetória histórica. Inicialmente, na década de 1960, desenvolvimento era sinônimo de produtividade, industrialização acelerada da agricultura, assim como do surgimento de complexos agroindustriais, responsáveis por intensas modificações nas dinâmicas produtivas. Na sequência, surgem os chamados pacotes tecnológicos, elementos cruciais na promoção da Revolução Verde, que tinha como foco principal a industrialização da agricultura. Essa percepção do desenvolvimento se esgota no início da década de 1970, pois os governos não conseguiam mais dar o suporte financeiro necessário, assim como o agravamento das condições de pobreza de parte da população rural é intensificado (WEISHEIMER, 2013).

A partir da década de 1990, o debate sobre o desenvolvimento rural ganha novas dimensões. O reconhecimento da agricultura familiar como categoria política, o redirecionamento de ações do Estado no rural, especialmente em relação à agricultura familiar, mudanças de caráter político e ideológico fundamentadas na dicotomia agricultura familiar/agricultura patronal, e a discussão sobre a sustentabilidade ambiental (SCHNEIDER, 2010) dão os traços para um novo olhar sobre o desenvolvimento rural.

O desenvolvimento rural não encontra uma definição específica. Vários autores buscam defini-lo, ou, ao menos, delinear elementos que o componham, na tentativa de melhorar as condições de vida das populações rurais. Dessa forma, a inclusão da perspectiva de gênero fazse pertinente para o estudo de perspectivas que buscam por um desenvolvimento rural.

As posições socioeconômicas ocupadas por homens e mulheres, especialmente no rural, historicamente foram - e ainda são - marcadas por assimetrias de poder entre os sexos que estabelecem as relações de gênero. Essas relações são determinantes na distribuição do 
trabalho, da renda, dos fatores de produção, dos recursos naturais e do direito à terra. Contudo, a presença e a participação das mulheres no rural estão intensamente relacionadas à transmissão de costumes, valores e tradições, ultrapassando os limites da produção, seja de atividades agrícolas e não agrícolas (NARCISO; HENRIQUES, 2008).

Os autores ainda salientam que a adoção da perspectiva de gênero possibilita melhor conhecimento e compreensão de dinâmicas presentes no rural, pois explicita as desigualdades de gênero materializadas nas atividades desenvolvidas por homens e mulheres, na distribuição do poder, no acesso a recursos e no posicionamento nos processos decisórios. A partir disso, com o intuito de colaborar para o reconhecimento da participação feminina e sua contribuição no desenvolvimento rural e nas dinâmicas que o compõem, justifica-se a iniciativa de explorar o tema da inserção da mulher na pecuária de corte.

A opção pela pecuária de corte sustenta-se na ideia de visibilizar a mulher inserida nessa atividade, pois a pecuária é uma atividade cultural e socialmente construída como de responsabilidade masculina. O campo é reconhecido como espaço de domínio da figura masculina, ou seja, se o campo é o espaço do homem, logo a pecuária é masculina (LUNARDI, 2012).

A partir disso, o objetivo é caracterizar a decisão gerencial de mulheres pecuaristas, residentes no município de Dom Pedrito, em sua atividade. Além disso, a problemática também contribui para dar visibilidade socioeconômica às mulheres, buscando sua legitimação como agentes potenciais na gestão de negócios rurais.

\section{Panorama da mulher inserida no meio rural}

No rural, os princípios das relações de gênero são os mesmos que os da sociedade como um todo, ou seja, várias vezes, a mulher é caracterizada por cuidar dos filhos, realizar serviços domésticos, envolver-se com produções mais leves, e, ainda, essas atividades acabam não sendo consideradas como trabalho.

Observando os princípios das famílias rurais do século XX, pode-se perceber a diferença estabelecida entre homens e mulheres. Esses aspectos eram - e muitas vezes ainda são característicos de famílias rurais do Rio Grande do Sul, pois a sucessão da terra era baseada no princípio do trabalho, ou seja, quem trabalha diretamente na terra tem direito a sua posse (SILVA; SCHNEIDER, 2010). Antigamente, dava-se um lote de terra para o filho herdeiro e, para a filha, um dote e um enxoval, já que, com o casamento, a mulher passava a fazer parte da família do marido, que tinha de sustentar sua esposa.

Outra situação pertinente ao tema é a que retrata Fernandes (2008) sobre o trabalho produtivo e o trabalho reprodutivo. Os homens são responsáveis pelas atividades produtivas, ou seja, os cuidados com a lavoura, criações de grande porte e comercialização de produtos que irão representar a maior parte da economia da propriedade, e a mulher ficaria destinada aos trabalhos reprodutivos, como cuidados domésticos, criação dos filhos, atividades produtivas menores, entre outros.

Um estudo de Silva e Schneider (2010) aponta que as noras substituem as filhas nas famílias rurais, pois as filhas estão saindo do meio rural para estudar, enquanto que as noras acompanham os filhos (maridos), permanecendo ali. Este estudo apresentou outra característica 
interessante: é aquela na qual as mulheres passam a chefiar as propriedades em função de viuvez, divórcio ou até mesmo por permanecerem solteiras, evidenciando a força da tradição patriarcal.

Desse modo, o conceito de gênero justifica a distinção, construída socialmente, entre as atribuições tidas como femininas e masculinas, e indica elementos que identificam os valores das atividades praticadas por mulheres e homens. Essa construção irá atuar claramente sobre os costumes, práticas e regras sistematizadas a partir da lógica delineada socialmente (MARTINS: BANDEIRA; CAPUTO, 2014).

O rural passou por diversas modificações ao longo dos períodos, assumindo novas características, inserindo a tecnologia e buscando a diversificação das atividades no meio produtivo, tanto agrícola como pecuário. Nesse sentido, Souza e Silva (2012) abordam que, da mesma forma, abre-se espaço para a inserção da mulher em atividades diversificadas dentro ou fora da propriedade. Entretanto, no rural, esse processo é mais dificultoso do que no urbano, pois, nas situações citadas anteriormente (viuvez, divórcio, etc.), em que a mulher assume o empreendimento rural, ainda há discriminação por parte da sociedade no que tange à figura feminina na atividade rural. Encontram-se dificuldades de escoamento de produção em função de obstáculos impostos nas negociações, e dificuldades de informações práticas, em virtude da adaptação à situação (SOUZA; SILVA, 2012).

As atividades femininas são percebidas apenas como extensão de suas obrigações, sendo assim, consideradas como "ajuda". Essa distinção também é suposta a partir da identificação do trabalho "leve" e do trabalho "pesado", os quais, respectivamente, seriam próprios das trajetórias feminina e masculina, constituindo-se essas contrariedades essenciais nas construções culturais (cada "cultura" estabelece o cunho de atividade leve ou pesada) (BRUMER, 2004).

Entretanto, a participação da mulher no meio rural é fundamental para a sustentação das atividades agrícolas, pois acumulam obrigações que se alternam entre os afazeres domésticos e as atividades de produção. O ambiente público e o privado vão ao encontro dessa lógica patriarcal em que a divisão sexual do trabalho se consolida, isto é, o contato com o ambiente público tange à supremacia dos homens, e o privado envolve as mulheres, reforçando sua invisibilidade. Os trabalhos leves, anteriormente destacados, percebidos como forma de "ajuda", pertencem às mulheres, desde jovens até o matrimônio, sendo sua atividade vista como auxílio ao marido (AMORIM; EUCLIDES; FIÚZA, 2010).

A partir disso, algumas perspectivas buscam novas reflexões sobre as atribuições naturalizadas como intrínsecas às mulheres. Uma das primeiras demandas que surge refere-se ao reconhecimento das mulheres rurais como trabalhadoras rurais. A condição de trabalhadora rural foi conquistada através da inclusão do nome nas notas de venda do produtor, fato que não gerou descontentamento por parte dos homens, já que não perderam seu poder e ainda houve um acréscimo dos recursos advindos do governo. Para as mulheres, isso representou um acréscimo tanto em termos materiais como simbólicos, pois sua participação como trabalhadora é reconhecida através da visualização e valorização de seu trabalho (BRUMER, 2004).

Situações como esta possibilitam a expansão do olhar sobre construções estabelecidas socialmente, oportunizando uma nova visão sobre a identidade da mulher rural, e auxiliam na 
desconstrução dos aspectos que dificultam sua atuação em espaços coletivos, permitindo-lhes a identificação como sujeito de sua própria história (AMORIM; EUCLIDES; FIÚZA, 2010). Contudo, a divisão construída entre o espaço público (assumido pelo homem), como ambiente político e produtivo, e o espaço privado (assumido pela mulher), como mantenedora das relações pessoais, reprodutivas e familiares, reitera a invisibilidade da mulher como ator político (MARTINS; BANDEIRA; CAPUTO, 2014).

A conciliação de elementos econômicos e políticos são fatores que contribuem fortemente na inserção das mulheres nos processos de desenvolvimento. Então, a partir das ideias expostas, reporta-se para uma especificidade da temática abordada, ou seja, mulheres inseridas na gestão da atividade pecuária, com o intuito de explorar essas situações, referenciando seu potencial para a produção.

Para alcançar, ao menos em parte, sua autonomia, a mulher rural passa a ter de administrar seu tempo entre trabalho doméstico e atividades remuneradas (BUTTO et al., 2014). Talvez, em função disso, visualizem-se, no rural, mulheres mais dedicadas a trabalhos para autoconsumo, sem a atribuição de renda. Porém, mesmo assim, há um acréscimo no número de mulheres que passam a assumir a responsabilidade exclusiva pelo grupo familiar (FARIA, 2011). Este fenômeno pode ser considerado como recente na sociedade brasileira e traz consigo a potencialidade de quebrar paradigmas, pois a ocorrência possibilita uma oposição ao sistema dominante, predeterminado pelas ideologias de gênero.

\section{Apontamentos para a compreensão da problemática: pecuária de corte e a gestão rural}

A pecuária de corte, no Brasil, configura-se como uma atividade relevante para a economia nacional, destaque tanto em âmbito econômico quanto social e cultural. Esta atividade, além de movimentar a produção propriamente dita, envolve os demais elos da cadeia produtiva, tais como insumos, distribuição e comercialização, implicando a geração de empregos diretos e indiretos.

O desenvolvimento histórico da pecuária brasileira deu-se juntamente com a expansão da fronteira agrícola, agregando aos sistemas extensivos de produção novas áreas de terra. Com a implantação de programas de crédito rural, na década de 1970, iniciaram-se diversas mudanças tecnológicas e, na década de 90 , com a abertura comercial do país, observou-se um cenário de modificações para o setor.

Essas alterações repercutiram na eficiência dos sistemas de produção, aumentando os indicadores tecnológicos de produtividade da bovinocultura de corte. Com isso, a atividade passou por um processo de profissionalização e inserção de processos tecnológicos, como a suplementação estratégica, cruzamentos, novas variedades forrageiras e outros, que permitiram aumentar a eficiência dos ciclos de produção (BARCELLOS et al., 2004).

Em relação à estrutura da cadeia produtiva da carne bovina, Wilkinson e Rocha (2005) identificam sete principais elos: indústria de insumos, pecuaristas, indústrias de abate e preparação de carne, distribuidores (atacado e varejo) e consumidores finais, internos e externos, e serviços de apoio, como pesquisa, vigilância sanitária. Na pecuária de corte, o elo do 
pecuarista, a produção, pode ser dividido em pontos: cria (produção de terneiros), recria (cria de terneiros e novilhas) e engorda (terminação dos animais para o abate).

Com o avanço tecnológico na produção de bovinos de corte, os índices produtivos encontraram significativos avanços, porém a heterogeneidade dos sistemas produtivos, atrelada às deficiências na gestão, resulta em um produto final não padronizado. A atividade pode ser lucrativa, desde que haja capacitação gerencial dos produtores e colaboradores, crédito acessível, melhorias no manejo dos animais e pastagens, dentre outros fatores (QUADROS, 2005).

No Rio Grande do Sul, a bovinocultura de corte está associada à ocupação do território e sua formação socioeconômica. A atividade é encontrada nas diferentes regiões do estado, considerada a primeira de importância econômica e, atualmente, abrange uma diversidade de sistemas de produção que refletem sua realidade complexa (SEVERO; MIGUEL, 2006).

Com as mudanças na conjuntura econômica e política, aos poucos, foi sendo introduzida a agricultura na região, especialmente por meio do cultivo do arroz, mas a bovinocultura de corte continuou sendo atividade produtiva destaque em área e quantidade de produtores (RIBEIRO, 2009). No entanto, grande parte dos pecuaristas gaúchos caracteriza-se por seu perfil, que os define como pecuarista tradicional, isto é, a inovação tecnológica ocupou reduzida parte das propriedades pecuaristas, já que a atividade é mais frequentemente desenvolvida por motivos de satisfação pessoal e segurança econômica do que visando ao lucro (RIBEIRO; QUADROS, 2015).

Outro tipo de pecuarista que se constitui ao longo da história foi o pecuarista familiar, o qual utiliza, predominantemente, a mão de obra familiar, e suas áreas contemplam no máximo 300 hectares. Com a redução de áreas das estâncias, a produção em grande escala, como ocorria em tempos passados, é impossibilitada, porém a pecuária de corte permanece como atividade principal e ainda desenvolvida de forma extensiva em áreas menores (RIBEIRO; QUADROS, 2015).

É notório que a bovinocultura de corte se apresenta como uma atividade destaque no estado, principalmente em função de seu vínculo com a história rio-grandense, entretanto o setor tem sofrido uma série de modificações, especialmente no que tange à relação das atividades agrícolas com as commodities. E, em função das especificidades da bovinocultura de corte, são perceptíveis as oscilações entre períodos de preços altos e baixos, influenciando diretamente as decisões gerenciais do produtor (ANDREATTA, 2009).

As especificidades das atividades agropecuárias dificultam a utilização de ferramentas gerenciais, pois grande parte não as considera. Independentemente de tratar-se de produções em âmbito agrícola ou pecuário, essas particularidades estão presentes na produção rural e são verificadas pelas seguintes condições: sazonalidade de disponibilidade de matéria-prima e do consumo do produto final, variações na qualidade da matéria-prima e perecibilidade tanto do produto final quanto dos insumos (BATALHA; SILVA, 2008).

Outros elementos também devem ser lembrados no que tange às especificidades das produções rurais, como, por exemplo, qualidade e vigilância sanitária, aspectos sociológicos, biológicos e condições edafoclimáticas dos alimentos. A primeira refere-se à exigência do consumidor acerca da qualidade e segurança dos alimentos; a segunda, aos aspectos 
sociológicos dos alimentos, abarcando as mudanças sociais e culturais atravessadas pela sociedade, e resultando, várias vezes, em mudanças no consumo; e a última talvez seja a mais potencial em termos de interferência nos resultados produtivos, pois a produção é diretamente dependente das condições biológicas e edafoclimáticas do ambiente (ZUIN; QUEIROZ, 2007).

Em termos gerenciais, parte dos reflexos nos produtos agropecuários, decorrentes das especificidades, poderia ser amenizada pela gestão rural. Porém a gestão rural, várias vezes, é percebida como atividade de segundo plano, pois a produção propriamente dita, mesmo que decorrente de condições históricas e culturais, tende a exigir mais atenção do proprietário. Outro aspecto relevante refere-se ao caráter centralizador das decisões gerenciais atribuídas ao chefe da família, predominantemente, do sexo masculino, também repercutindo na ideia de que as questões administrativas geram apenas custos (ANDREATTA, 2009).

Além da centralização da figura masculina na gestão agropecuária, Melo (2003) constatou duas perspectivas acerca dos gestores. Os autocráticos, que se destacam nos aspectos produtivos, porém têm maiores dificuldades de sucessão, e, os democráticos, que abrem espaço para discussão com esposa e filhos, sobressaindo-se em termos de inovação e motivação, dispondo de maior tranquilidade no processo sucessório.

Além disso, a habilidade gerencial feminina também ganha espaço, como, por exemplo, por meio da liderança interativa, cujo intuito é a redução de ambição pessoal e o desenvolvimento dos demais envolvidos na organização. Há estudos e avaliações de desempenho, onde as mulheres pontuam significativamente à frente dos homens em aspectos relativos ao impulso da comunicação, motivação e capacidade de ouvir, mostrando-se como um eficiente modo de gerenciamento para as organizações contemporâneas (DAFT, 2010).

\section{Metodologia}

Este estudo caracteriza-se por apresentar elementos que o definem como estudo de caso múltiplo, pois, de acordo com Roesch (2010), o estudo de caso pode variar entre único ou múltiplo, o que vai concordar com as unidades de análise que podem ser de um ou mais indivíduos, organizações, unidades geográficas ou eventos. Dessa forma, as informações foram geradas a partir de entrevistas realizadas com mulheres pecuaristas, no intuito de conhecer como se dá o processo gerencial da atividade.

O município de Dom Pedrito, considerado o quinto maior município em extensão territorial do Rio Grande do Sul, apresenta uma área de 5.192,095 Km², está localizado na Mesorregião da Campanha do Sudoeste e Microrregião da Campanha Meridional e sua população estimada é de 39.886 habitantes (IBGE, 2014). Sua distância até a capital, Porto Alegre, representa $441 \mathrm{Km}$, e os seus limites territoriais são, ao norte, os municípios de Rosário do Sul, São Gabriel e Lavras do Sul; ao leste, Bagé; ao oeste, Santana do Livramento; ao sul, a República Oriental do Uruguaia (DOM PEDRITO, 2013).

A Região da Campanha é conhecida pela sustentação econômica vinculada às atividades agropecuárias, especialmente o cultivo de arroz e soja e a pecuária de corte. O município de Dom Pedrito, assim como o Rio Grande do Sul, tem sua formação sócio-histórica atrelada à 
inserção dos bovinos. No ano de 2014, o rebanho estimado foi de 386.909 cabeças de bovinos (IBGE, 2014).

A identificação das participantes, num primeiro momento, deu-se em contato com uma produtora rural com o objetivo de confirmar a presença de mulheres envolvidas na gestão da pecuária de corte. Confirmada a suposição, os encaminhamentos para a identificação das participantes se deram por meio de indicações potenciais da própria produtora rural, assim como de contato com a Inspetoria Veterinário do município e o Sindicato Rural.

$\mathrm{Na}$ sequência, a Inspetoria Veterinária realizou um levantamento de dados, para verificar o número de mulheres cadastradas, chegando a uma totalidade de 132 mulheres. Entretanto, do total de cadastros foram identificadas 32 pecuaristas que efetivamente estariam à frente da propriedade; destas 26 eram residentes no município. Partindo da livre escolha de participar ou não da pesquisa, foram realizados convites às mulheres, resultando, ao final, um número de 20 entrevistas.

O primeiro contato com as participantes se deu por meio do convite que thes foi feito; posteriormente, realizou-se contato telefônico, com a finalidade de convidá-las para um momento de exposição do projeto e confirmação das participações. Na sequência, as entrevistas foram agendadas conforme disponibilidades das participantes. As entrevistas dividirem-se em três blocos: caracterização/gênero, pecuária e gestão rural/decisões.

Por contar com questões abertas e fechadas, a análise dos dados se deu da seguinte forma: os dados qualitativos, pela análise de conteúdo; os dados quantitativos, pela verificação estatística, por meio de frequência, moda, média e desvio-padrão. A ferramenta utilizada para a sistematização dos dados deu-se por meio de planilhas do Microsoft Excel, resultando em gráficos e tabelas para melhor visualização.

\section{Resultados e discussão}

A gestão de propriedades rurais tem sido historicamente conduzida por homens, principalmente, em virtude das marcas históricas que delineiam grande parte das dinâmicas sócio produtivas no rural. Em função disso, buscou-se identificar os participantes ativos no processo gerencial das propriedades praticantes da pecuária de corte, tendo por base a visão das mulheres inseridas nesse processo.

Em se tratando da tomada de decisão relativa à produção e negócios pecuários, $65 \%$ das respondentes (figura 1) afirmaram que a atividade é desenvolvida em conjunto, reportando a várias situações, como, por exemplo, participação da entrevistada, irmãos, administradores externos, marido, pais e filhos. A tomada de decisão exclusivamente individual representou $30 \%$ do total, e $5 \%$ apenas teve o marido como responsável pelas decisões produtivas e econômicas. Este cenário conduz ao que Melo (2003) observou sobre as perspectivas de gestores autocráticos e democráticos.

Os gestores autocráticos possuem maior eficiência em aspectos produtivos, porém apresentam dificuldades no processo sucessório. Em contrapartida, os gestores democráticos caracterizam-se por abrir espaço para ideias vindas de seus familiares, aproximando esse delineador ao modo gerencial das mulheres entrevistadas, pois, como se observou, mais da 
metade delas participam ou estão à frente de uma gestão em conjunto, compartilhando ideias com familiares e agentes técnicos, possibilitando alternativas no que concerne às decisões de negócio, e permitindo a inserção de sucessores no processo.

Figura 1 - Agentes atuantes na decisão produtiva

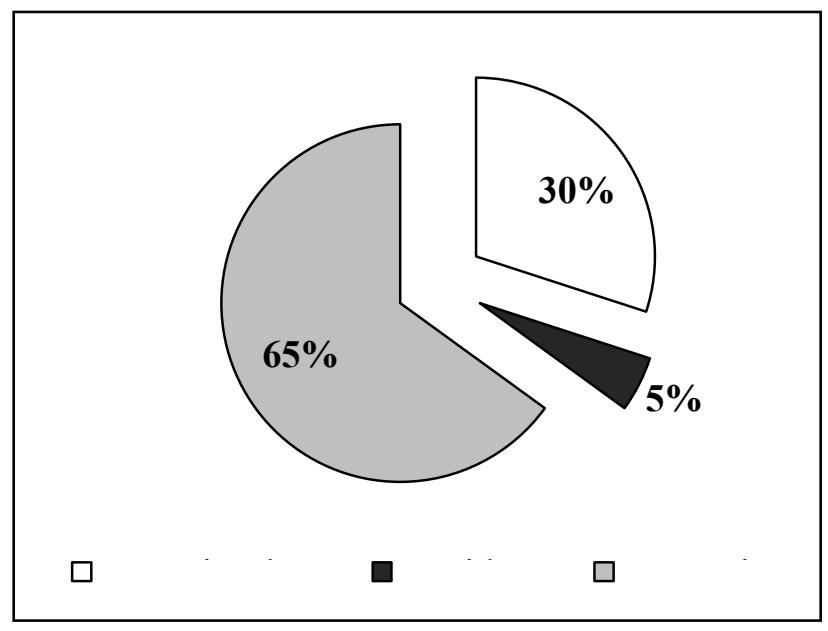

Fonte: Dados da pesquisa, 2013.

Na sequência, abordou-se acerca de fatores pontuais, visando verificar o grau de importância e o seu potencial na tomada de decisão gerencial por parte das mulheres. Nessa questão, foram atribuídas notas que variaram de um a cinco, correspondentes aos seguintes graus de importância: 1 - Nada Importante; 2 - Pouco Importante; 3 - Importância Relativa; 4 - Importante; 5 - Muito Importante. Os aspectos considerados podem ser visualizados na tabela 1.

Tabela 1 - Grau de importância de fatores associados à tomada de decisão

\begin{tabular}{lrrrr}
\hline Fatores associados à tomada de decisão & Mínimo & Máximo & Média & $\begin{array}{c}\text { Desvio } \\
\text { Padrão }\end{array}$ \\
\hline Clima & 4 & 5 & 4,76 & 0,43 \\
Capacidade de uso do solo & 4 & 5 & 4,64 & 0,49 \\
Tradição familiar & 1 & 5 & 3,05 & 1,39 \\
Possibilidade de lucro & 4 & 5 & 4,58 & 0,50 \\
Disponibilidade de recursos financeiros & 4 & 5 & 4,35 & 0,49 \\
Risco da atividade & 3 & 5 & 4,52 & 0,62 \\
\hline
\end{tabular}

Fonte: Dados da pesquisa, 2013.

O primeiro fator abordado, o clima, obteve a maior média $(4,76)$ e o menor desviopadrão $(0,43)$, quando comparado aos demais aspectos considerados, e suscitou duas vertentes de opiniões acerca de sua importância para as decisões. A primeira explica que o clima é um 
dos aspectos incontroláveis, sujeito a fortes consequências na produção, compatibilizando com o mencionado por Litre (2010).

A autora salienta algumas características climáticas do meio pampeano, classificando-o como "[...] propenso aos eventos climáticos extremos", tais como secas e inundações (LITRE, 2010, p. 213). A segunda vertente exposta pelas entrevistadas explica que o clima é importante, porém o planejamento é fundamental para as decisões, sendo que as previsões climáticas auxiliam na preparação às intempéries. Uma entrevistada ainda enfatiza que o clima define situações, mas não é a única resposta para as perdas. Isso pode demonstrar a visão gerencial da mulher, pois se considerou o clima como fator importante nas decisões, propostas a partir das previsões preestabelecidas.

O segundo fator, capacidade de uso do solo, considera o meio ambiente e o campo nativo como itens fundamentais nos processos produtivos, obtendo-se as mesmas notas do primeiro fator, mínima quatro e máxima cinco. Porém, a média baixou ligeiramente para 4,64, e o desvio-padrão, consequentemente, aumentou para 0,49. O item destaca a conscientização acerca da utilização adequada do solo, pois o aspecto foi considerado como importante (4) e muito importante (5). A visão de gestão das entrevistadas permite enfatizar a sua preocupação em ocupar as diferentes áreas com as devidas possibilidades de criação ou cultura que potencializem a produção e, ao mesmo tempo, preservem o recurso natural em questão.

O terceiro item, a tradição familiar, foi o que causou maiores variações entre as menções por parte das entrevistadas. A análise oportunizou esta visualização, pois a nota mínima foi um, e a máxima foi cinco, resultando em uma média de 3,05 e desvio-padrão de 1,39. A partir de observações nas entrevistas, as percepções, assim como os comentários, induziram ao entendimento de que aquelas que atribuíram notas mais elevadas para este quesito, fizeram-no pelo fato da família estar presente na pecuária por várias gerações, contudo foram poucas as manifestações que levaram a identificar um pensamento mais fechado acerca de inovações na atividade.

Aquelas que atribuíram notas mais baixas, em alguns casos, não possuíam tradição familiar na atividade pecuária. Em relação a este ponto, Andreatta (2009) constatou que os valores não econômicos da atividade, como a tradição familiar, ao serem relacionados a fatores como produtividade e rentabilidade são, várias vezes, priorizados pelos pecuaristas, deixando os demais em segundo plano. Embora a tradição familiar seja mencionada, percebe-se que a visão de negócio também está presente na fala das participantes, isto é, a tradição familiar e os aspectos diretos da produção são considerados de maneira conjunta, visando resultados satisfatórios.

O quarto fator, possibilidade de lucro, contemplou nota mínima quatro e máxima cinco, média 4,58 e desvio-padrão 0,50. Esse aspecto obteve uma posição semelhante aos dois primeiros abordados. A perspectiva de obtenção de lucro se faz presente nas decisões gerenciais das entrevistadas, entretanto Andrade (2010) ressalta que essa visão com fins econômicos nem sempre reflete a realidade dos sistemas agrários. Contudo, conseguiu-se notar um equilíbrio entre percepções de lucro e objetivos mais amplos, envolvendo aspectos não econômicos. 
Os últimos dois fatores, disponibilidade de recursos financeiros e risco da atividade, podem estar associados. O primeiro destes obteve nota mínima quatro, máxima cinco, média 4,35 e desvio-padrão 0,49; o segundo, nota mínima três, nota máxima cinco, média 4,52 e desvio-padrão 0,62. A associação entre os dois fatores foi apontada por uma entrevistada que enfatiza a preferência por baixos riscos, pois prefere trabalhar com seu capital disponível a retirar crédito e ficar em débito por longos períodos.

Entretanto, a partir dos dados encontrados, percebe-se a disponibilidade de recursos financeiros como um fator de importância significativa nas decisões da atividade, atrelado ao risco dessa atividade, face à improbabilidade dos resultados em função de uma alternativa escolhida para atingir objetivos já estabelecidos (DAFT, 2010). Essas ocorrências moldam as características de decisão por parte das entrevistadas.

O estilo de decisão de mulheres pecuaristas também foi investigado, no intuito de, ao menos, apontar algumas das características que o compunham. Os itens considerados na construção dos estilos de decisão podem ser visualizados na tabela 2, sendo que o método de análise se baseou na frequência com que tais eventos ocorrem no momento das decisões gerenciais, segundo as entrevistadas. A atribuição da frequência deu-se da seguinte forma: 1 - nunca, 2 - pouco frequente, 3 - frequência relativa, 4 - frequente, 5 - muito frequente.

Tabela 2 - Estilos de decisão na atividade pecuária

\begin{tabular}{lcccr}
\hline \multicolumn{1}{c}{ Estilos de decisão } & Mínimo & Máximo & Média & $\begin{array}{r}\text { Desvio } \\
\text { Padrão }\end{array}$ \\
\hline Decisão racional & 3 & 5 & 4,40 & 0,75 \\
Decisão emocional & 1 & 4 & 2,47 & 1,12 \\
Decisões baseadas em números & 3 & 5 & 4,35 & 0,78 \\
Usa sua experiência & 3 & 5 & 3,89 & 0,87 \\
Usa experiência de seus pais & 1 & 5 & 2,63 & 1,38 \\
Consulta à família & 1 & 5 & 3,52 & 1,54 \\
Redes sociais p/ comercialização & 1 & 5 & 1,63 & 1,11 \\
Acompanhamento dos resultados & 3 & 5 & 4,57 & 0,69 \\
Exerce liderança & 3 & 5 & 4,31 & 0,74 \\
Decisões reflexivas e demoradas & 2 & 5 & 3,18 & 0,91 \\
Decisões ágeis e rápidas & 2 & 5 & 3,57 & 0,96 \\
Decisões centralizadas & 1 & 5 & 2,68 & 0,94 \\
Decisões compartilhadas & 2 & 5 & 3,87 & 0,95 \\
\hline Fonte: Dados da pesquisa, 2013. & & & &
\end{tabular}

Fonte: Dados da pesquisa, 2013.

O primeiro item, decisões racionais, obteve nota mínima três, máxima cinco, média 4,4 e desvio-padrão de 0,75 , demonstrando as oscilações nas notas atribuídas. Os dados 
encontrados indicaram que $85 \%$ das entrevistadas tomam decisões racionais muito frequentemente ou sempre. Isso pode referenciar o potencial do gerenciamento feminino, pois, conforme Andrade (2010, p. 60), a racionalidade pressupõe que, a partir do conhecimento das alternativas disponíveis, seja escolhida aquela que atender mais eficientemente à equação que "[...] maximiza o resultado para dado insumo, ou que minimiza o insumo para dado resultado". As decisões emocionais alternaram-se consideravelmente, não alcançando a nota máxima, ou seja, obteve-se nota mínima um, nota máxima quatro, média correspondente a 2,47 e desvio-padrão de 1,12. Essa situação pode ser positiva, pois mostra que o emocional é utilizado de maneira ponderada nas decisões sobre a produção.

A sensibilidade emocional, assim como a facilidade em trabalhar em rede, a conciliação entre diversas tarefas e outras especificidades tidas como talentos naturais femininos são alguns dos fatores requisitados nas organizações contemporâneas (FISCHER, 2001 apud TONANI, 2011). Essas características, vistas como apropriadas para os negócios da atualidade, passam a potencializar a presença de mulheres nos negócios, especialmente em se tratando de mulheres que já atuam, ou, ao menos, participam e colaboram com as decisões.

As decisões baseadas em números identificaram a frequência com que as gestoras costumam fazer uso, para as tomadas de decisões, dos controles de custos, assim como da análise dos preços disponibilizados no mercado. Do mesmo modo que a primeira questão, a decisão racional atingiu notas entre três e cinco, média de 4,35 e desvio-padrão de 0,78, indicando uma pequena redução de valores quando comparados à primeira questão.

As decisões em negócios rurais, especialmente na pecuária de corte, devem ser avaliadas levando em consideração "os números", pois, muitas vezes, são eles que traduzem o quanto será ganho nas operações produtivas e financeiras. Na bovinocultura de corte, por consequência de suas especificidades, ocorrem oscilações sazonais de preços, influenciando diretamente nas decisões (ANDREATTA, 2009). Analisando as respostas das entrevistadas, percebe-se que há a preocupação em acompanhar custos e preços para uma tomada de decisão mais satisfatória, concordando com o exposto por Andreatta (2009).

A experiência própria como auxílio nas decisões refere-se diretamente ao tempo de atuação na atividade. As notas foram as mesmas obtidas no item anterior: média de 3,89 e desvio-padrão de 0,87 , refletindo maior variação na frequência atribuída. A contribuição de Ploeg (1990 apud RIBEIRO, 2009) menciona o que foi encontrado, ou seja, as experiências anteriores no ambiente de produção podem definir as práticas a ações a serem tomadas no desenvolvimento da atividade. Embora algumas das participantes tenham considerado a frequência relativa nesse caso, percebe-se que a experiência adquirida com a atividade é um elemento significativo no momento da tomada de decisão, pois nenhuma pecuarista mencionou pouca frequência ou nunca para o item.

Já a utilização da experiência dos pais concentrou uma das questões que apresentou maiores variações, alternando entre nota mínima um e máxima cinco, média 3,89 e desviopadrão 1,38, o maior até então encontrado. Este fator está atrelado a discussões anteriores, como, por exemplo, a importância da tradição familiar nas decisões de produção. Talvez seja por isso que expresse maiores variações, pois $26,32 \%$ das participantes indicaram frequência nula, já que algumas entrevistadas não possuíam famílias tradicionalmente na atividade. 
Entretanto, as opções frequentes, muito frequente e sempre resultaram em uma somatória de $52,63 \%$, destacando o papel da transmissão de ensinamentos acerca da atividade pecuária. Nessa mesma linha, questionou-se sobre a frequência de consulta à família nas decisões, e os números novamente apresentaram variações entre nota mínima um e máxima cinco, atingindo uma média de 3,52 e desvio-padrão de 1,54, sendo superior à da questão anterior.

Esta ocorrência acerca das três maiores frequências indicou mais de $70 \%$ das respondentes, confirmando o que já havia sido observado, ou seja, a presença de atividades participativas no que tange às decisões por parte das mulheres pecuaristas. Em termos gerais, a gestão rural revela aspectos que a conduzem de maneira centralizada na figura do chefe ou responsável, predominantemente do sexo masculino (ANDREATTA, 2009). Contudo, nota-se que, ao se tratar de mulheres inseridas nas atividades de gestão, a tendência reporta a ações mais coletivas e democráticas, contribuindo para a visibilidade feminina em posições sociais até então construídas como masculinas.

Outro item mencionado foi o das redes sociais para comercialização, obtendo novamente os extremos em notas referentes às frequências, onde a média reduziu consideravelmente $(1,63)$ e o desvio-padrão indicou variações acerca das menores frequências, pois o maior percentual foi obtido pelas entrevistadas que nunca fizeram uso da ferramenta com este fim (63,16\%). Em contrapartida, houve uma delas que relatou fazer uso das redes sociais apenas para comercialização. Nesse sentido, Andreatta (2010) constatou em seu estudo que a participação em redes sociais, com fins comerciais, caracterizou médios e grandes produtores, correspondendo aos poucos casos constatados neste estudo, entretanto a maioria não faz uso dessa ferramenta.

Como item discutido na caracterização dos estilos de decisão, também foi abordada a frequência do acompanhamento dos resultados conseguintes às decisões. A frequência mínima correspondeu a três; a máxima, a cinco; a média foi de 4,57 e o desvio-padrão de 0,69. Os percentuais demonstraram que apenas $10,53 \%$ acompanham os resultados de maneira frequente, o que já demonstra um resultado satisfatório, porém os outros $89,47 \%$ alternaramse entre muito frequente e sempre. Os dados apresentados concordam com o exposto por Melo (2003), pois a autora salienta que acompanhamento e avaliação dos resultados obtidos é uma das etapas que envolvem um processo de tomada de decisão.

A frequência com que as entrevistadas acreditam exercer liderança sobre o negócio pecuário também foi questionada. As notas variaram entre três e cinco, média de 4,31 e desvio-padrão de 0,74 , representando que a totalidade indicou, no mínimo, exercer liderança frequentemente; $36,84 \%$ salientaram muito frequente; $47,37 \%$ sempre. Esses resultados podem ser vistos como avaliações de desempenho que, de acordo com Daft (2010), podem ser um meio de comprovar o estilo de liderar feminino adequado para as organizações atuais, abrangendo aspectos que impulsionam a comunicação, motivação e capacidade de ouvir, as quais, com outras, estão sendo vistas como potenciais para aumentar a eficiência do setor administrativo.

As decisões reflexivas e demoradas, assim como as ágeis e rápidas, obtiveram resultados semelhantes, apresentando nota mínima dois e máxima cinco, média de 3,18, desvio-padrão de 
0,91, e média de 3,57 e desvio-padrão de 0,96, respectivamente. As situações apresentaram resultados semelhantes em função de sua complementariedade, pois algumas entrevistadas salientaram a relatividade das situações para com cada tipo de decisão: as decisões reflexivas e demoradas relacionam-se às decisões não costumeiras, e as decisões ágeis e rápidas refletem situações mais rotineiras.

Tanto é que a opção frequente, referente às decisões reflexivas e demoradas, apresentou um percentual de 56,25\%, sendo que, nas decisões ágeis e rápidas, o maior percentual $(42,11 \%)$ esteve em muito frequente, até mesmo por esse tipo de decisão ser mais rotineira. As decisões centralizadas obtiveram nota mínima de um e máxima de cinco, média de 2,68 e desvio-padrão de 0,94. O maior percentual (50\%) concentrou-se em pouco frequente (2), e, nas decisões compartilhadas, a nota mínima foi de dois e a máxima de cinco; média 3,87 e desvio-padrão de 0,95.

Os percentuais distribuíram-se em três parcelas idênticas $(31,25 \%)$, que variaram entre as alternativas frequente, muito frequente e sempre, e apenas $6,25 \%$ responderam pouco frequente. Novamente, percebe-se o potencial participativo das decisões de caráter feminino partindo da realidade estudada, reafirmando o que os autores explanam acerca da liderança interativa.

A partir das análises expostas, o grupo entrevistado, de modo geral, apresentou entendimentos semelhantes no que se refere às variáveis consideradas para o alcance de um gerenciamento eficiente, conforme as possibilidades e a realidade de cada negócio. Em relação aos estilos de decisão, apesar de algumas variações entre as entrevistadas, notam-se semelhanças, como, por exemplo, ênfase nas decisões racionais, no acompanhamento dos resultados, nas decisões baseadas em números e no exercício de liderança, isto é, em aspectos diretamente influenciáveis em decisões gerenciais. $\mathrm{Na}$ sequência, serão dispostas as considerações finais pertinentes a este artigo.

\section{Considerações finais}

Inicialmente, é importante enfatizar as relações das entrevistadas com a atividade pecuária, em grande parte, decorrentes de tradição familiar na atividade. Historicamente, as gerações antecessoras, na pecuária de corte, são vistas como conservacionistas e centralizadoras, porém ressalta-se que as participantes da pesquisa passam a inserir seus próprios estilos de gerenciamento e processos decisórios, ponderando os aprendizados familiares com os aspectos contemporâneos de gerenciamento, como, por exemplo, a gestão participativa.

Decorrente de modificações nas relações de poder imersas no ambiente familiar, há um rompimento nos estilos de decisão, majoritariamente caracterizados como centralizador e baseados na figura masculina. O empoderamento econômico feminino pode ser visto como uma dessas possíveis mudanças, permitindo que as relações de dependência se fragilizem e repercutam em novas configurações, possibilitando a superação de visões que destinam a mulher ao doméstico exclusivamente. 
Elementos de análise como clima, capacidade de uso do solo, tradição familiar, possibilidade de lucro, disponibilidade de recursos financeiros e risco da atividade refletiram racionalidades gerenciais, mesmo que algumas entrevistadas incluam correntes mais tradicionais. Um exemplo disso foi a disponibilidade de recursos financeiros e os riscos da atividade, que apresentaram uma abordagem associada. A primeira mostrou-se como fundamental para o andamento do negócio, e o segundo atrelou-se às improbabilidades da atividade, sendo a busca por recursos financeiros considerada como um fator de risco na atividade, embora a maioria tenha costume de fazer.

Os estilos de decisão encontrados variaram bastante; entretanto, notou-se aspectos semelhantes entre as entrevistadas, como, por exemplo, ênfase nas decisões racionais, no acompanhamento dos resultados, nas decisões baseadas em números e no exercício de liderança, sendo esses aspectos influenciáveis em decisões de negócio. As decisões centralizadas apresentaram uma média baixa, enfatizando a participação de outros agentes no negócio. Outro aspecto a ser destacado é o acesso às informações por intermédio da internet, meio mais citado, demonstrando a inserção das tecnologias da informação e comunicação (TIC's) nos casos estudados.

Ressalta-se o potencial da mulher pecuarista frente ao gerenciamento da atividade, cujos aspectos fundamentais estão atrelados às suas particularidades como fator diferenciador nos processos de tomada de decisões e gestão da atividade pecuária. Assim, a forma tradicional de condução de um estabelecimento familiar rural vai aos poucos se reformulando e demonstrando as possibilidades que auxiliam a inserção da mulher em perspectivas diferentes das comumente vivenciadas.

\section{Referências}

AMORIM, Érika Oliveira; EUCLIDES, Maria Simone; FIÚZA, Ana Louise de Carvalho. Sindicalizadas rurais e ativistas políticas: uma nova face do empoderamento da mulher no meio rural. In: VIII CONGRESSO LATINOAMERICANO DE SOCIOLOGIA RURAL, 2010, Porto de Galinhas. Anais: Porto de Galinhas: Alasru, 2010.

ANDRADE, Maria Margarida de. Introdução à Metodologia do Trabalho Científico. 10. ed. São Paulo: Atlas, 2010.

ANDREATTA, Tanice. Bovinocultura de corte no Rio Grande do Sul: um estudo a partir do perfil dos pecuaristas e organização dos estabelecimentos agrícolas. Tese (Doutorado em Desenvolvimento Rural) - Programa de Pós-Graduação em Desenvolvimento Rural, Universidade Federal do Rio Grande do Sul, Porto Alegre, 2009.

BARCELLOS, Júlio Otávio Jardim et al. A bovinocultura de corte frente a agriculturização no Sul do Brasil. In: XI Ciclo de Atualização em Medicina Veterinária - CAMEV, 11, 2004, Lages.

Anais... . Lages: CAV/UDESC, 2004.

BATALHA, Mário Otávio; SILVA, Andrea Lago da. Gerenciamento de sistemas agroindustriais: definições, especificidades e correntes metodológicas. In: BATALHA, Mário Otávio. Gestão Agroindustrial: GEPAI - Grupo de Estudos e Pesquisas Agroindustriais. 3. ed. v.1 São Paulo: Atlas, 2008. 
BRUMER, Anita. Gênero e agricultura: a situação da mulher na agricultura do Rio Grande do Sul. Revista Estudos Feministas, Florianópolis, v. 1, n. 12, p. 205-227, jan./ab. 2004.

BUTTO, Andrea et al. (Org.). Mulheres rurais e autonomia: formação e articulação para efetivar políticas públicas nos territórios da cidadania. Brasília: Ministério do Desenvolvimento Agrário, 2014.

DAFT, Richard. Administração. São Paulo: Cengage Learning, 2010.

DOM PEDRITO. História de Dom Pedrito. Disponível em:

<http://www.dompedrito.com.br/dom-pedrito/historia-de-dom-pedrito.aspx>. Acesso em: 18 mar. 2013.

FARIA, Nalu. Desafios para a construção da autonomia econômica da mulher. In: FUNDAÇÃO ALEXANDRE DE GUSMÃO. Autonomia econômica e empoderamento da mulher: textos acadêmicos. Brasília: Fundação Alexandre de Gusmão, 2011. p. 229-248.

IBGE. Instituto Brasileiro de Geografia e Estatística. IBGE Cidades, 2014. Disponível em: <http://www.cidades.ibge.gov.br/xtras/temas.php?lang=\&codmun=430660\&idtema=147\&sear ch=rio-grande-do-sul|dom-pedrito|pecuaria-2014>. Acesso em: 25 mai. 2016.

LITRE, Gabriela. Os gaúchos e a globalização: vulnerabilidade e adaptação da pecuária familiar no pampa do Uruguai, Argentina e Brasil. Tese (Doutorado - Centro de Desenvolvimento Sustentável) - Universidade de Brasília - IHEAL/CREDAL, Paris III, Sorbonne-Nouvelle, 2010.

LUNARDI, Raquel. Mudanças nas relações de trabalho e gênero no turismo rural. Tese (Doutorado em Desenvolvimento Rural) - Programa de Pós-graduação em Desenvolvimento Rural, Universidade Federal do Rio Grande do Sul, Porto Alegre, 2012.

MARTINS, Clitia Helene Backx; BANDEIRA, Marilene Dias; CAPUTO, Paula Maria. Condição de vida das mulheres e desigualdades de gênero no Rio Grande do Sul. In: MARTINS, Clitia Helene Backx (Org.). Estudos das condições das mulheres e das desigualdades de gênero existentes no Estado do Rio Grande do Sul. Porto Alegre: Fee, 2014. p. 8-48.

MELO, Vânia Lícia de Figueirêdo. Influência das características dos sistemas de gestão no processo sucessório de unidades de produção familiar em São Luiz Gonzaga - RS. Dissertação (Mestrado em Agronegócio - Programa de Pós-graduação em Agronegócios) - Universidade Federal do Rio Grande do Sul, Porto Alegre, 2003.

NARCISO, Vanda; HENRIQUES, Pedro Damião de Souza. O Papel das Mulheres no Desenvolvimento Rural: Uma Leitura para Timor-Leste. Working Paper. Évora: CEFAGE-EU, 2008.

QUADROS, Danilo Gusmão de. Sistema de produção de bovinos de corte. Salvador: Universidade do Estado da Bahia, 2005.

RIBEIRO, Claudio Marques. Estudo do modo de vida dos pecuaristas familiares da Região da Campanha do Rio Grande do Sul. Tese (Doutorado em Desenvolvimento Rural - Programa de Pós-graduação em Desenvolvimento Rural) - Universidade Federal do Rio Grande do Sul, Porto Alegre, 2009.

RIBEIRO, Claudio, M.; QUADROS, Fernando Luiz Ferreira de. Valor histórico e econômico da pecuária. In: PILLAR, Valério de Patta; LANGE, Omara. Os campos do Sul. Porto Alegre: Rede Campos Sulinos - UFRGS, 2015. p. 19-30. 
ROESCH, Sylvia Maria Azevedo. Projetos de estágio e de pesquisa em administração: guia para estágios, trabalhos de conclusão, dissertações e estudo de caso. 3. ed. São Paulo: Atlas, 2010.

SCHNEIDER, Sergio. Situando o desenvolvimento rural no Brasil: o contexto e as questões em debate. Revista de Economia Política, São Paulo, v. 30, n. 3, p. 511-531, jul./set. 2010.

SEVERO, Christiane Marques; MIGUEL, Lovois de Andrade. A sustentabilidade dos sistemas de produção de bovinocultura de corte do Estado do Rio Grande do Sul. REDES, Santa Cruz do Sul, v. 11, n 3, p. 213-234, set./dez. 2006.

SILVA, Carolina Castilho; SCHNEIDER, Sergio. Gênero, Trabalho Rural e Pluriatividade. In: SCOTT, Parry; CORDEIRO, Rosineide; MENEZES, Marilda (Orgs.) Gênero e Geração em Contextos Rurais. Florianópolis: Mulheres, 2010. p. 183-207.

SOUZA, R. E. M. de; SILVA, M. G. S. N. Mulher: a quebra do paradigma da função reprodutiva. Revista Geografares, Vitória, n. 10, p. 203-224, mar. 2012.

TONANI, A. V. Gestão feminina- um diferencial de liderança mito ou nova realidade. In: CONGRESSO NACIONAL DE EXCELÊNCIA EM GESTÃO. 7. ed. Anais do CNEG. Rio de Janeiro: CNEG, 2011.

WANDERLEY, Maria de Nazareth Baudel. A ruralidade no Brasil moderno: por um pacto social pelo desenvolvimento rural. In: GIARRACCA, Norma. ¿Uma nueva ruralidade em América Latina? Buenos Aires: Consejo Latinoamericano de Ciencias Sociales, 2001.

WEISHEIMER, Nilson. Desenvolvimento rural, capitalismo e agricultura familiar. Revista Olhares Sociais, Cachoeira, v. 2, n. 1, p. 51-78, maio, 2013.

WILKINSON, John; ROCHA, Rudi. Uma análise dos setores de carne bovina, suína e de frango. Rio de Janeiro: Projeto SENAI, 2005.

ZUIN, Luis Fernando Soares; QUEIROZ, Timóteo Ramos. Agronegócios: Gestão e Inovação. São Paulo: Saraiva, 2007. 